${ }^{1}$ Qatar University, Doha, Qatar ${ }^{2}$ Penn State University, University Park, Pennsylvania, USA

*Email: aikhlef@qu.edu.qa http://dx.doi.org/

$10.5339 /$ nmejre.2013.4

Submitted: 26 February 2013 Accepted: 12 June 2013

(C) 2013 Ikhlef, Knight, licensee Bloomsbury Qatar Foundation Journals. This is an open access article distributed under the terms of the Creative Commons Attribution License CC BY 3.0, which permits unrestricted use,

distribution and reproduction in any medium, provided the original work is properly cited.

\section{Conditions for student-centered teaching and learning in Qatari elementary math and science classrooms: Relationship between classroom processes and achievement of curriculum standards}

Atmane Ikhlef ${ }^{1, \star}$, Stephanie L. Knight ${ }^{2}$

\section{ABSTRACT}

Qatar K-12 school reform emphasizes student-centered classrooms where students actively engage in enquiry and use their critical thinking and problem solving skills. Classrooms characterized by these elements should emerge as more successful on Qatari standards-based assessments, but little research has been done to examine the relationship between these characteristics and standards attainment. This study investigated the conditions for student-centered teaching and learning through examination of teacher and student perceptions, and student achievement in math and science classrooms in higher and lower achieving elementary schools. Data were collected in 17 schools randomly selected from 46 schools that had implemented the standards for at least 3 years. Findings indicate that the percentage of standards met by schools is very low and the incidence of classroom behaviors associated with student-centered classrooms is also very low across schools. However, schools making more progress meeting standards tended to exhibit higher levels of student-centered behaviors. The implications of these findings for professional development and the implementation of reform in Qatar were discussed. 


\section{INTRODUCTION}

A key requirement of Qatar's educational reform is the ability of teachers working in the "Education for a New Era" schools to adopt student-centered instructional approaches and to implement studentcentered classroom practices and activities, which can promote deep conceptual learning, knowledge construction and intellectual autonomy (www.education.gov.qa). The present study was designed to investigate the classroom behaviors and processes associated with student-centered teaching and learning and their relationship with achievement of curriculum standards was. This study is a part of a large research project that was conducted to evaluate the impact of Qatari education reform policy "Education for a New Era" on classroom processes and student learning outcomes. The study reported here was built on the data generated by the initial phase of the project, which looked more closely at how teachers in Qatari independent elementary schools were implementing student-centered instructional practices in the elementary math and science classrooms. ${ }^{1}$

The K-12 education reform in Qatar has initiated major changes in the school education system including establishment of national curriculum standards, national professional standards for teachers; emphasis on critical thinking and problem solving skills through student-centered teaching; and extensive teacher professional development. ${ }^{2,3}$ In the classroom, the reform provides "an emphasis on encouraging a spirit of inquiry and hands-on learning" often referred to as student-centered teaching because students are actively involved in activities and discussions that promote deep conceptual learning, knowledge construction, and autonomy. Within this framework, the teacher's key role is to develop student critical thinking and problem solving skills and create student-centered learning environments that facilitate student active participation in classroom activities and foster student self-regulation. ${ }^{4-7}$ In this paper, we report results from a study of the conditions for student-centered teaching and learning in Qatari independent elementary schools, and provide an analysis of the relationship between classroom processes, teacher and student perceptions and achievement of curriculum standards. Further in-depth analysis of related survey data can be found in., ${ }^{1,8,9}$

\section{THEORETICAL FRAMEWORK}

The current Qatari educational curriculum standards emphasize student-centered classrooms where students actively engage in inquiry and problem solving. This focus suggests that certain models of learning, ${ }^{4,5}$ pedagogical approaches and professional development ${ }^{10,11}$ form the framework of the goals of Qatari reform., ${ }^{1,9}$ These constructivist-based models emphasize the importance of a deep foundational knowledge, student use and monitoring of learning goals and strategies, effective use of technology, development of dispositions for critical thinking and reflection, and the need for professional development based on learning science principles. ${ }^{1,11}$ Classrooms characterized by these conditions should emerge as more successful on Qatari standard-based assessment. However, little research has been carried out to investigate the conditions for student-centered teaching and learning related to standards attainment.

\section{Teaching and learning in student-centered classrooms}

Past research on teacher attributes and student behaviors in student-centered classrooms has identified a number of key features that characterize the student-centered learning environment. In the student-centered classroom, instruction focuses on the student, and the teacher provides support to students, demonstrates flexibility with curriculum choices, utilizes a variety of assessments, and facilitates active engagement of students. ${ }^{12,13}$ Studies that examined more closely classroom processes in student-centered classrooms have focused their attention on student engagement, as a key predictor of student achievement and success. ${ }^{14}$ Engagement involves students demonstrating positive academic behaviors such as listening, speaking, answering questions, high levels of on-task behavior, intellectual autonomy, and regulation of motivation and learning strategy use.

While emerging research evidence tends to suggest that teaching in Qatari independent schools is student-centered, ${ }^{15}$ additional research work needs to be done to examine more closely the practices related to learner-centered instruction and to determine whether these processes do exist in the Qatari school context. 


\section{Learning environment in student-centered instruction}

Previous studies of the relationships between the psychosocial aspects of the learning environment and student's behaviors and learning have consistently reported strong associations between student's perceptions of their learning environment and achievement of learning goals. ${ }^{16-19}$ Specifically, classroom learning environments which are perceived positively tend to lead to better learning outcomes. Existing research evidence suggests that classroom learning environments characterized by autonomy, participation and other elements of active engagement emerge as more successful with regard to student achievement. ${ }^{20,21}$ Although some studies that have been conducted in non-western countries confirmed some of these findings, ${ }^{19,22}$ additional research on the characteristics of the classroom learning environments in student-centered classrooms in the Arab context is needed to gain more understanding of this important research field.

\section{THE PRESENT STUDY}

Although, prior research work has been carried out to evaluate the implementation of the Qatari K-12 education reform, ${ }^{15}$ few studies to date have actually been conducted to examine more closely the classroom processes related to student-centered teaching and learning in Qatar's elementary schools. Therefore, the purpose of this study was to investigate the conditions for student-centered teaching and learning through examination of teacher and student perceptions, and student achievement in math and science classrooms in higher and lower achieving elementary schools. Specifically, the research questions were:

(1) To what extent do students engage in meaningful conceptual learning in math and science classes in independent elementary schools?

(2) To what extent do students perceive a student-centered learning environment?

(3) To what extent do students report self-regulated learning (motivation and strategy use) during math and science classroom activities?

(4) To what extent do teachers perceive that they are implementing instruction consistent with reform focused on inquiry and standards attainment related to student-centered instruction?

(5) How effective do teachers perceive themselves to be when providing student-centered instruction in math and science classrooms?

(6) How do the conditions for student-centered teaching and learning in higher- and lowerperforming elementary schools differ?

\section{METHODS}

This study employed a descriptive design using systematic classroom observations and teacher and student surveys to determine observed and perceived conditions for student-centered teaching and learning with a stratified random sample of math and science classrooms in independent schools.

\section{Participants}

Participants included teachers and students from a sample of math and science classrooms in Qatari independent elementary schools. Elementary schools were targeted since recognition of the need to use strategies for self-regulation of motivation and problem solving begins between the ages of 5-10 years and reflection on students' own learning continues to develop throughout their elementary school years. ${ }^{5}$ We have little information on students' cognitive development for complex learning during this age period ${ }^{23}$ and study of this age group will add to the knowledge base. The study was confined to math and science classes since the inquiry targeted by the Qatar reform is rooted in specific disciplines. Data were collected over an academic year in 17 schools that were randomly selected from 46 schools that had implemented the Qatar standards for at least 3 years. Three to five third and fourth grade math and science classrooms were randomly selected from these schools for participation. The sample included 67 teachers and approximately 1150 students.

\section{Procedures}

The extent to which interactions and activities in the classroom were student-centered was determined through observations using the Teacher Attributes Observation Protocol (TAOP). ${ }^{24}$ In addition, off-task behavior was calculated to determine student opportunity for learning. 
The TAOP is a combined qualitative and quantitative measure (qualitative scripting followed by a set of summative likert-type items which are completed based on the qualitative data) designed to capture contructivist approaches to teaching. The summative set of likert-type items represent seven constructs (conceptual understanding, reflection, student active participation, $\mathrm{x}$ real world applications, consideration of diversity, challenging curriculum, and assessment) consisting of 27 indicators. Interrater reliability was .79 for the TAOP and internal consistency reliability was .93. Observers divided the class into five equal segments and recorded off-task behaviors of students in the class at each interval. Between intervals, observers took notes and recorded examples of interactions related to the seven components of the TAOP. At the end of the class period, they completed the likert-type instrument with items pertaining to each of the seven constructs. Items ranged from o (not observed) to 4 (observed very often).

Teachers were asked to conduct a 'typical' class on the observation day and were observed for the duration of the math or science lesson. While the observations do not provide an exhaustive profile of classroom interactions, they provide a snapshot of what is occurring on a given day in Qatari elementary math and science classrooms $(n=56)$.

In addition to observations, perceptions of teachers and students related to the conditions for student-centered teaching and learning were obtained through a variety of teacher and student surveys. During their free period, math and science elementary teachers $(n=67)$ were administered a modified version of the Teacher Efficacy Scale (TES) developed by ${ }^{25}$ and the Inventory for Teaching and Learning (ITAL). ${ }^{26}$ The TES consists of 16 items in two scales: Personal Teaching Efficacy, which represents a teacher's perceptions of her ability to affect student learning, and General Teaching Efficacy which represents teachers' beliefs about the general relationship between teaching and learning. Teachers completed the ITAL to determine their perceptions of instructional practice and the extent to which they engaged in practices consistent with Traditional, Standards-based, and Inquiry teaching. Reliability for the TES is .98 and .95 for the ITAL.

On a day separate from the classroom observations, students completed the Individualized Classroom Environment Questionnaire (ICEQ; ${ }^{16,27}$ ) and the How Do You Solve Problems inventory (HDYSP) to determine perceptions of classroom environment, self-regulation strategy use, and problem-solving. The ICEQ contains five scales: Personalization, Participation, Independence, Investigation, and Differentiation and exhibits internal consistency reliability of .79. The HDYSP consists of 25 items in five scales (Problem Representation, Objectivity, Evaluation, Knowledge, and Monitoring Subtasks) measuring students' problem solving and self-regulation perceptions. Internal consistency reliability for the HDYSP is .79. Each survey required approximately 30 minutes to complete and was administered by a native Arabic speaker who provided assistance or translations as needed.

Results from the Qatar Comprehensive Educational Tests (QCET) were obtained for each school in math/science from reports of the. ${ }^{28}$ Three classification lists were issued which, when considered together, give a picture of overall performance of schools in three areas: extent to which schools meet standards; level of academic achievement, and academic progress from 2007-2008. Each list was divided into three levels of schools depending on performance. For purpose of this analysis, sample schools in the top tier of the three lists were used to define higher-performing schools in comparison with schools in the remaining tiers, which were considered lower-performing. The results yielded 6 schools in the top tier for Meets Standards, two of which were included in our sample; 18 schools in the top level of Academic Achievement, five of which were included in our sample; and 10 schools in the Overall Change Academic Outcomes 2007-2008, four of which were included in our sample. Since some schools in our sample were represented in the top of more than one level, the total number of higher-performing schools was 8 schools. From the lower-performing tiers of the three lists, 9 schools were included in our sample. However, some data are missing from schools in both groups. Descriptive data for the conditions related to student-centered teaching and learning were analyzed qualitatively for each group.

\section{RESULTS AND DISCUSSION}

To address the research questions, descriptive statistics were calculated for all variables. Analyses of Variance (ANOVA) and Multivariate Analyses of Variance (MANOVAs) were used to determine differences in observations of teacher and student classrooms behaviors and students' and teachers' perceptions of their learning environments by school performance level (higher and lower-performing schools). 


\section{Observed teacher and student behaviors}

The Teacher Attributes Observation Protocol investigated the nature of the content of classroom instruction, including depth of conceptual understanding elicited and the degree to which the curriculum challenged students (Table 1). In addition, student off-task behavior was calculated from the time-samples of off-task behavior at preset intervals. Results were low overall $(M=.56 ; S D=.48)$, with the key elements of student-centered instruction such as: Real World Applications ( $M=.23$; $\mathrm{SD}=.26)$, Active Student Participation (M .37; SD =.33), and Differentiation in Strategies and curriculum ( $M=.51 ; S D=.39)$ observed rarely. Teaching for Conceptual Understanding ( $M=.86$; $\mathrm{SD}=.31)$ and Challenging Curriculum $(\mathrm{M}=.84 ; \mathrm{SD}=.03)$ were observed more often than other variables, but were still low. Again there was considerable variation across schools, perhaps due to differences in teachers' ability to implement student-centered instruction. While conditions for student-centered teaching and learning were low overall, student off-task behavior was high, with students off-task almost one third of the time they spent in class.

Contrary to the findings of the ${ }^{15}$ study, overall, the results of the present study do not provide evidence, at this point, of successful implementation of the educational reform in Qatar. Observations depict very little student engagement in discipline-based activities in ways that lead to self-regulation and motivation. While there was considerable variation as noted by the standard deviations (see Table 1), percentages were generally low across classrooms for discipline-based content and activities that underlie student-centered instruction. Comparing the amount of off-task behavior and kinds of activities observed does not support the existence of conditions for student-centered teaching that lead to deep conceptual learning by students.

Results indicated that students overall were off-task and not productively engaged in about a third of class time. This is disturbing since it reflects reduced opportunity for student learning of any type. This finding may be related to the type of school. Classroom management in boys' schools is perceived as more difficult than in girls' schools (Personal Communication with Qatar University professor) and higher off-task rates in boys' schools, which comprised 7 of 17 schools included in the analysis, could have affected off-task level. Comparison of off-task rates revealed about $10 \%$ more in boys' schools, and the range for off-task was much greater compared to girls'. The off-task level for both girls' and boys' schools may be related to difficulties in teacher management of higher-level learning activities noted in previous research. ${ }^{14,29}$

\section{Teachers' perceptions of instruction and efficacy}

Contrary to the results of the observations, teachers perceived they emphasized more elements associated with student-centered inquiry than traditional teacher-centered instruction (see Table 2 below). Means for Standards-based teaching $(M=5.31 ; S D=.55)$ and Inquiry teaching $(M=5.11$; $\mathrm{SD}=.26)$ were similar and high. This would indicate that teachers perceived they were implementing student-centered inquiry instruction and is in contrast to the low levels of conditions for student-centered instruction actually observed. The mismatch between teacher perceptions and observed behaviors needs to be considered by those implementing the reform as well as those providing professional development for teachers. Perhaps familiarity with the curriculum standards and awareness of expectations gave them the illusion of student-centered inquiry. During one observation, the field notes taken between off-task sweeps indicated that a particular teacher would turn to the

Table 1. Teacher attributes observation protocol and student off-task means and standard deviations $(n=56)$.

\begin{tabular}{lll}
\hline Attributes & Mean & SD \\
\hline Total student off task & 29.66 & 19.34 \\
Conceptual understanding & .86 & .66 \\
Reflection & .64 & .65 \\
Real world applications & .23 & .36 \\
Active student participation & .37 & .40 \\
Differentiation & .50 & .39 \\
Challenging curriculum & .84 & .69 \\
Assessment & .48 & .61 \\
Total TAOP & .56 & .48 \\
\hline
\end{tabular}

Note: Scales range from o (Not Observed) to 4 (Observed Very Often) 
Table 2. Teachers' perceptions of instruction and efficacy: means and standard deviations.

\begin{tabular}{lcc}
\hline & Mean & SD \\
\hline I. Inventory for Teaching and Learning* $(n=67)$ & & \\
$\quad$ Standards-based instruction & 5.31 & .55 \\
Traditional instruction & 3.78 & .57 \\
$\quad$ Inquiry-based instruction & 5.11 & .26 \\
II. Teacher efficacy & & \\
$\quad$ Total sample $(n=67)$ & 4.11 & 1.68 \\
$\quad$ General teaching efficacy & 5.41 & .89 \\
$\quad$ Personal teaching efficacy & & \\
${ }^{*}$ Scales range from 1 (No Emphasis) to 6 (Very Strong Emphasis). & & \\
${ }^{*}$ Scales range from 1 (Strongly Disagree) to 6 (Strongly Agree). & &
\end{tabular}

observer frequently and give the 'label' for the instruction she was providing (e.g., this is tying the content to student lives). However, the observer noted that the examples were either incorrect or at a low level and that students were not involved actively in instruction.

This mismatch between actual strategy use and teacher perceptions of strategy use may represent an initial stage in moving from teacher-centered to student-centered instruction. In fact, although observations revealed low levels of conceptual understanding and challenging curriculum, these variables were higher than other elements of student-centered inquiry instruction and may be emerging in the classroom.

Similar to perceptions of instruction consistent with the new reform, teachers reported high efficacy for student-centered teaching. Teachers with high teaching efficacy typically impact students more positively than low-efficacy teachers. ${ }^{30,31}$ In this study, teachers reported high levels of Personal Teaching Efficacy and somewhat lower levels of General Teaching Efficacy (see Table 2). In other words, they had less confidence that other teachers teach in ways consistent with development of problem solving and self-regulation, but they perceived they personally could impact student performance in these areas. This is consistent with findings of other research. ${ }^{30,31}$ However, the high efficacy did not appear to generate positive findings for this study. The finding that teachers in independent schools have high efficacy may follow the pattern seen in novice teachers. When teachers first interact with students as interns supervised by cooperating teachers and university supervisors, they report high efficacy for teaching. This efficacy falls considerably when they experience their first year of teaching after the internship. ${ }^{32}$ Teachers in independent schools may be experiencing initial high efficacy which may fall as they encounter difficulties in implementation of the standards related to student-centered inquiry instruction.

Also, confidence alone may not be enough to implement reform. Results from the qualitative field notes of observations indicated that teachers were doing most of the talking in English. Students were doing very little talking in English. The lack of English proficiency among students may have contributed to the observation findings of a lack of student-centeredness. Students' confidence in their English proficiency and their opportunity to participate in linguistically appropriate tasks are key elements since students would benefit most from an active role in classroom discussion. ${ }^{33}$

Table 3. Students' surveys: means and standard deviations.

\begin{tabular}{lcc}
\hline & Mean & SD \\
\hline I. Individualized classroom environment questionnaire* $(n=1151)$ & \\
Personalization & 4.11 & 1.30 \\
Participation & 3.66 & 1.41 \\
Independence & 2.15 & 1.41 \\
Involvement & 3.42 & 1.44 \\
Differentiation & 2.82 & 1.60 \\
II. How Do You Solve Problems* $(n=1151)$ & & \\
Problem representation & 4.06 & 1.22 \\
Objectivity & 4.03 & 1.25 \\
Evaluation & 4.15 & 1.18 \\
Knowledge & 3.76 & 1.42 \\
Subtask monitoring & 4.01 & 1.19 \\
\hline * Scales range from 1 (Strongly Disagree) to 5 (Strongly Agree). & &
\end{tabular}


Table 4. Classroom observations by higher- and lower-performing schools: means and standard deviations

\begin{tabular}{|c|c|c|c|c|}
\hline & Mean & SD & & \\
\hline \multicolumn{5}{|c|}{ I. Teaching attributes observation protocol* } \\
\hline High-performing $(n=8)$ & .54 & .34 & & \\
\hline Low-performing $(n=9)$ & $\begin{array}{l}.57 \\
\text { LPS }\end{array}$ & $\begin{array}{l}.44 \\
\text { HPS }\end{array}$ & & \\
\hline Student off-task behaviors ${ }^{\star \star}$ & 30.53 & 20.16 & 29.05 & 18.99 \\
\hline
\end{tabular}

The findings indicate that teachers' ability to facilitate this confidence and proficiency and scaffold classroom discussion needs to be further investigated.

\section{Students' perceptions of learning and learning environment}

Self-regulation refers to students' dispositions and strategies (motivation, persistence, and strategy use) that enable them to achieve learning goals related to inquiry and problem solving. ${ }^{34}$ Students reported high levels of problem-solving/problem representation $(M=4.06 ; S D=1.22)$ and self-regulation (objectivity $M=4.03$; $S D=1.25$; evaluation $M=4.15 ; S D=1.18$; and subtask monitoring $M=4.01 ; S D=1.19$ ) with the exception of one area (see Table 3). Students reported less knowledge $(M=3.76$; $S D=1.42)$ available for problem solving. This finding may be related to observation data described previously that reported low levels of conceptual understanding and challenging curriculum - the knowledge base was not provided.

Students' perceptions of classroom environment that facilitates development of self-regulation were more mixed. Students reported high degrees of Personalization $(M=4.11 ; S D=1.30)$ and Participation $(M=3.66 ; S D=1.41)$ and to a lesser extent, Involvement $(M=3.42 ; S D=1.44)$. However, students' perceptions of Independence $(M=2.15 ; S D=1.44)$ and teachers' Differentiation $(M=2.82 ; S D=1.60)$ of student work/activities were considerably lower. While results of the Inventory for Teaching and Learning (see Table 3 ) indicated that teachers perceived they gave students opportunities for autonomy and individualized assignments/ activities according to Qatari standards, students did not perceive these elements to the same extent. Students felt that teachers gave them personal attention, cared for them, and gave them opportunities for participation and involvement in class activities. However, without autonomy and differentiation, student-centeredness perhaps could not be fully achieved. ${ }^{35}$ Findings from student perceptions of learning environment are more consistent with observed classroom behaviors than teachers' perceptions.

\section{Conditions for student-centered instruction in higher- and lower-performing schools}

Tables 4-6 provide results of the comparison of higher-performing schools (HPS) and lower-performing schools (LPS). Findings indicated few differences by performance level, perhaps because both achievement and behaviors related to standards were quite low. The top tier of Meeting Standards only achieved $10-20 \%$ of standards. ${ }^{28}$

The Teacher Attributes Observation Protocol, which focused on instruction from a constructivist perspective consistent with the standards, showed very low, but similar use overall by both groups (see Table 5), with LPS exhibiting slightly more use of behaviors associated with student-centered instruction than HPS. Off-task behavior was similar with slightly higher off-task behavior in LPS. Differences were not statistically different, although the effect sizes for off-task behavior and student-centered activities were medium, indicating some practical significance. However, the lack of large differences in achievement and instructional behaviors make it difficult to determine differences by school performance.

Results from teacher (see Table 5) surveys showed some differences by school performance. Teachers in both HPS and LPS reported similar high levels of efficacy for teaching in reform-oriented schools. However, differences across groups were consistent with the findings from the classroom observations when teachers were asked about the type of instruction they provided in classrooms. While there were no significant differences between LPS and HPS for teacher reports (see Table 5) of either Standard-based $(F=.31 ; p=.58)$ or Inquiry teaching and Learning $(F=1.1 . ; p=.30)$, 
Table 5. Teacher surveys by higher- and lower-performing schools: means and standard deviations

\begin{tabular}{lcccc}
\hline & \multicolumn{2}{c}{ High-performing $(n=7)$} & & \multicolumn{2}{c}{ Low-performing $(n=8)$} \\
\cline { 2 - 3 } & Mean & SD & & Mean \\
\hline I. Teacher efficacy* & & & SD \\
GTE & 4.20 & 1.69 & 4.25 & .55 \\
PTE & 5.42 & .79 & 5.43 & .67 \\
Total & 4.82 & 1.24 & 4.84 & .11 \\
II. Inventory for teaching and learning & 5.25 & .81 & 5.40 & .89 \\
Standards & 3.91 & 1.30 & 3.78 & .82 \\
Traditional & 5.09 & .81 & 5.22 & .82 \\
Inquiry & &
\end{tabular}

* Scales range from 1 (Strongly Disagree) to 6 (Strongly Agree)

${ }^{* *}$ Scales range from 1 (No Emphasis) to 6 (Very Strong Emphasis).

HPS teachers perceived significantly higher Traditional teaching and learning $(F=5.38 ; p=.02)$. These findings are consistent with the trends noted in the observations for student-centered variables, although the differences were not statistically significant in the observation analyses.

Students' perceptions of classroom environment (ICEQ instrument) and problem-solving (HDYSP instrument) were high and similar across groups (see Table 6). No significant differences emerged for the two types of schools $(F(1,13)=.000 ; p=.98)$ and effect sizes were generally small. In general, observations of inquiry practices were much lower compared to teacher and student reports of these practices. Students, however, were more consistent with observed findings.

In summary, some variations by achievement level were noted, with LPS exhibiting and teachers in LPS reporting slightly greater student-centeredness. Several explanations might address this unexpected finding. Since schools were randomly drawn from eligible schools, the possibility of bias should be mitigated. Nevertheless, due to teacher absenteeism, many substitutions had to be made, raising the possibility that teachers who were absent were somehow different than their colleagues who were present. In addition, some schools were unable to be observed due to scheduling problems. Scheduling observations was a major challenge due to scheduling uncertainties and last-minute changes that appear to be common in Qatari schools. In addition, the length of the observation may not have captured classroom teaching and learning to the extent needed, even if there were no problems with the schedule. However, since both LPS and HPS had similar problems with absenteeism and were observed for the same amount of time, these are probably not factors in the differences that emerged. Overall, the fact that multiple data sources support similar findings suggests that the limitations presented above probably were not responsible for the unexpected findings.

Another possibility is that the assessments may not be consistent with the standards. Teaching to the test, particularly if the test is more oriented to basic skills, often works against student-centered approaches. Traditional direct instruction has been successful in raising standardized test scores. ${ }^{36}$ Teachers in HPS report slightly more traditional instruction than teachers in LPS, an indication that this may be a possible factor in the results.

Another explanation is that student and teacher behaviors related to student-centeredness are emerging and have not yet been implemented to the extent that we can see a relationship between achievement and instruction. Overall, both observations and student outcomes indicate low levels of standards implementation. Additional investigation of barriers confronted in classrooms that might

Table 6. Student surveys by higher- and lower-performing schools: means and standard deviations.

\begin{tabular}{llr}
\hline & Mean & SD \\
\hline I. Individualized classroom environment questionnaire* & & \\
High-performing $(n=8)$ & 3.29 & .91 \\
Low-performing $(n=9)$ & 3.27 & .77 \\
II. How do you solve problems* & & \\
High-performing $(n=8)$ & 4.05 & 1.18 \\
Low-performing $(n=9)$ & 4.02 & 1.19 \\
\hline * Scales range from 1 (Strongly Disagree) to 5 (Strongly Agree). & &
\end{tabular}


contribute to low levels of implementation, including possibility of linguistic and cultural difficulties, needs to be conducted.

The dispositions for student-centered instruction, or at least awareness of the goals, are prevalent as indicated by teacher and student survey responses. However, teachers and students may not yet have acquired the skills needed to implement student-centered instruction and impact achievement. Change in performance may lag behind changes in teacher and student perceptions and dispositions due to the pressures this approach places on participants. ${ }^{34,37}$ The high student off-task rate signals problems in general with management of the new and often unfamiliar behaviors related to student-centeredness. That the classes in LPS have slightly higher off-task rates and evidence of student-centered activities but with lower achievement, supports the hypothesis of increased pressures due to the approach.

\section{LIMITATIONS OF THE PRESENT STUDY}

It should be noted that the data generated by the present study were collected in the early phases of the implementation of the K-12 education reform in Qatar, and frequent policy changes have since been made by the Supreme Education Council, ${ }^{15}$ after the current study was completed, which can significantly limit the validity of the study findings. For instance, English was the language of instruction in math and science subjects when our study was conducted; this is no longer the case today. Furthermore, recent research studies reported evidence suggesting more successful implementation of student-centered practices by teachers in Qatari independent schools, ${ }^{15}$ while the results of the current study showed limited evidence of full implementation of student-centered instruction in independent schools. Therefore the findings of the present may be limited to this specific phase of the reform's implementation in Qatar's schools in which it was carried out. Another possible limitation of the current study is to do with the fact that the extent of the implementation of student-centered instruction was investigated in math and science classrooms only, and the study findings were related to grades 3 and 4 math and science classrooms may not apply to other subjects areas. Furthermore, the study sample was restricted to elementary schools, and different results may be obtained with middle or secondary level samples. Finally, given the descriptive nature of the study, cause-effect relationships between student-centered variables and achievement of curriculum standards, as some of study results may suggest, are not to be inferred, confirmation of a causal relationship between these two variables requires the use of advanced experimental research designs.

\section{CONCLUSIONS AND IMPLICATIONS}

Findings from this study provide little evidence of implementation of student-centered learning environments in independent schools, and they point to a number issues and challenges related to classroom processes that may have impacted the actualization of student-centered teaching and learning. These findings also provide useful information about the conditions for student-centered teaching and learning that can potentially inform education policy makers in Qatar. Furthermore, these findings emphasize the need for more extensive and targeted professional development, which includes intensive practice and coaching, acquisition of complex behaviors, ${ }^{38}$ and change of teacher role consistent with the direction of the educational reform in Qatar. ${ }^{3,15}$

\section{Acknowledgements}

This study was funded by a grant from the Qatar National Research Fund, National Priorities Research Program, Grant \#13-6-7-1.

\section{REFERENCES}

[1] Knight S, Ikhlef A, Parker D, Joshi RM, Eslami Z, Sadiq H, Al-Ahraf M, Al Saai A. Investigation of math and science teaching and learning in Qatari independent elementary schools. In: Gitsaki C, ed. Teaching and Learning in the Arab world. New York: Peter Lang Publishers; 2011:249-274.

[2] Education Institute. National Professional Standards. Doha, Qatar: State of Qatar Supreme Education Council; 2002.

[3] Brewer D, Augustine C, Zellman G, Ryan G, Goldman C, Stasz C, Constant L. Education for a New Era: Design and Implementation of K-12 Education Reform in Qatar. Santa Monica, CA: Rand; 2007.

[4] In: Bransford JD, Brown AL, Cocking RR, eds. How People Learn: Brain, Mind, Experience, and School. Washington, DC: National Academy Press; 1999.

[5] In: Bransford J, Brown A, Cocking RR, eds. How People Learn: Brain, Mind, Experience, and School. expanded ed. Washington, DC: National Academy Press; 2000. 
[6] In: Minstrell J, van Zee E, eds. Inquiring into Inquiry Learning and Teaching in Science. Washington, DC: American Association for the Advancement of Science; 2000.

[7] Zimmerman B, Schunk D. Self-regulated Learning and Academic Achievement. Laurence Erlbaum; 2000.

[8] Knight S, Parker D, Zimmerman W, Ikhlef A. Investigating the relationship between perceived and observed studentcentered learning environments in Qatari elementary math and science classrooms. Learning Environment Journal. (In Press).

[9] Ikhlef A, Knight S. Conditions for student-centered teaching and learning: relationship between perceptions of classroom processes and school achievement of curriculum standards. Paper presented at the Annual Meeting of the American Educational Research Association, New Orleans, LA, April, 2011.

[10] Loucks-Horsley S, Hewson PW, Love N, Stiles KE. Designing Professional Development for Teachers of Science and Mathematics. Thousand Oaks, CA: Corwin Press; 1998.

[11] Putnam R, Borko H. What do new views of knowledge and thinking have to say about research on teacher learning? Educational Researcher. 2000;29(1):4-15.

[12] Motschnig-Pitrik R, Holzinger A. Student-centered teaching meets new media: concept and case study. Educational Technology \& Society. 2002;5(4).

[13] Sawyer K. Cambridge Handbook of the Learning Sciences. New york: Cambridge; 2006.

[14] Brophy J, Good T. Teacher behavior and student achievement. In: Wittrock MC, ed. Handbook of Research on Teaching. 3rd ed. New York: Macmillan; 1986.

[15] Zellman GL, Ryan GW, Karam R, Constant L, Salem H, Gonzalez G, Orr N, Goldman CA, Al-Thani H, Al-Obaidi K. Implementation of the K-12 Education Reform in Qatar's Schools. Rand Qatar Policy Institute; 2009.

[16] Fraser B, Fisher D. Development and validation of short forms of some instruments measuring student perceptions of actual and preferred classroom learning environment. Science Education. 1983;67:115-131.

[17] Fraser B. Classroom and school climate. In: Gabel D, ed. Handbook of Research on Science Teaching and Learning. New York: MacMillan; 1994:493-541.

[18] Fraser B. Science learning environments: assessment, effects, and determinants. In: Fraser B, Tobin K, eds. International Handbook of Science Education. Dordrecht, The Netherlands: Kluwer; 1998:527-564.

[19] Fraser B. Classroom learning environment. In: Abell S, Lederman N, eds. Handbook of Research on Science Education. Mahweh, NJ: Lawrence Erlbaum; 2007:103-124.

[20] Green BA, Miller RB, Crowson M, Duke BL, Akey L. Predicting high school students' cognitive engagement and achievement: contributions of classroom perceptions and motivation. Conemporary Educational Psychology. 2004;29:462-482.

[21] Jadullah N, Pounder D. Middle school reform and its relationship to learning environments and student outcomes. In: Hoy W, DiPaola M, eds. Studies in School Improvement. Charlotte, NC: Information age; 2009:95-136.

[22] Zedan R. New dimensions in the classroom climate. Learning Environments Research: An International Journal. 2010;13:75-88.

[23] In: Duschl R, Schweingruber H, Shouse A, eds. Taking Science to School: Learning and Teaching Science in Grades K-8. Washington, DC: National Research Council, National Academies Press; 2007.

[24] Fouts J, Brown C, Theiman G. Classroom Instruction in Gates Schools: A Baseline Report. Seattle, WA: The Bill and Melinda Gates Foundation; 2002.

[25] Gibson S, Dembo MH. Teacher efficacy: a construct validation. Journal of Ecuational Psychology. 1984;76:569-582.

[26] Ellet C, Monsaas J. Cross-Sample Validation of a Measure of Teaching and Learning Environments in Science and Mathematics. Paper presented at the Annual Meeting of the American Educational Research Association, Chicago, IL, 2007, April.

[27] Spinner H, Fraser B. Evaluation of an innovative math program in terms of classroom environment, student attitudes, and conceptual development. Paper presented at the annual meeting of AERA, New Orleans, LA, 2002, April.

[28] Supreme Education Council Evaluation Institute. Qatar comprehensive educational assessment (QCEA) 2009 results. Doha, Qatar: Supreme Education Council; 2010. . Retrieved from http://www. english.education.gov.qa/section/ sec/evaluation_institute/sao/_qcea

[29] Doyle W. Classroom organization and management. In: Wittrock MC, ed. Handbook of research on teaching. 3rd ed. New York: MacMillan; 1986:392-431.

[30] Tschannen-Moran M, Woolfolk Hoy A, Hoy WK. Teacher efficacy: its meaning and measure. Review of Educational Research. 1998;68:202-248.

[31] Tschannen-Moran M, Woolfolk Hoy A. Teacher efficacy: capturing an elusive construct. Teaching and Teacher Education. 2001;17(7):783-805

[32] Hoy AW, Spero RB. Changes in teacher efficacy during the early years of teaching: A comparison of four measures. Teaching and Teacher Education. 2005;21(4):343-356.

[33] Grassi E, Barker H. Culturally and Linguistically Diverse Exceptional Students. Thousand Oaks, CA: Sage; 2010.

[34] Schunk D, Zimmerman B. Motivation and Self-regulated Learning: Theory, Research, and Applications. New York: Lawrence Erlbaum; 2008.

[35] Reeve J, Ryan R, Deci E, Jang H. Understanding and promoting autonomous self-regulation: a self-determination theory perspective. In: Schunk D, Zimmerman B, eds. Motivation and Self-regulated Learning: Theory, Research, and Applications. New York: Lawrence Erlbaum; 2008:223-244.

[36] Good T, Brophy J. Looking in Classrooms. $8^{\text {th }}$ ed. New York: Longman; 2000.

[37] Boekaerts M. Self-regulated learning: where are we today. International Journal of Education Research. 1999;31:445-457.

[38] Hawley WD, Valli L. The essentials of effective professional development: a new consensus. In: Darling-Hammond L, Sykes G, eds. Teaching as the Learning Profession. San Francisco: Jossey Bass; 1999. 